\section{Oxford Handbook of Complementary Medicine}

Ernst, E; Pittler, M.; Wider, B.; Boddy, K. (eds)

Oxford, Oxford University Press, 2008, 448 pp, GBP 29,95

ISBN 978-0-19-920677-3

This is another well produced book from the Oxford Handbook series drawn from the Ernst stable and ever expanding database. I think that Professor Ernst has done an absolutely superb job in bringing together a huge amount of information with respect to complementary and integrated medicine over the years of his tenure at Exeter; this has been of enormous value and has been a major contribution to our understanding of CAM. It has really enabled researchers and clinicians to have a much clearer grasp of the evidence that actually exists and within the boundaries of the systematic review process, how it may be appraised. It represents a magnum opus that is of substantial clinical and academic value.

The main problem, however, is a somewhat eccentric interpretation that Ernst places on a number of issues which very largely disagree with opinions held by the majority of serious and balanced CAM researchers in the UK, US and Germany. Ernst would probably argue that all CAM researchers are unbalanced and his interpretation of the available evidence is the correct one. For instance, the diatribe on page 30 which looks at evidence based medicine or integrated medicine is more of a polemic than a rational argument clearly grounded in individual opinion rather than evidence. It is perhaps this seamless interchange between evidence and opinion that is difficult to deal with as both apparently seem equally 'true' in the Ernstian world. The second issue that always emerges in texts written by Ernst is an overemphasis on adverse reactions. In practice, this effectively means that individuals who take some common and very safe herbs such as Hypericum will appear in a GP's surgery frightened that they might actually bleed to death as a consequence because of the warnings with respect to anticoagulants, even if they have never taken an anticoagulant in their lives. I have had this happen to me in practice and it serves to emphasise that disproportionate warnings can be harmful! Information and evidence needs to be in context and it so rarely is when Ernst is talking about CAM. There are also some major errors of omission; dietary therapy is classified by most of the international and systematic classification systems as being a complementary medical approach. Yet, Ernst fails to mention the importance of any dietary therapy in diseases such as migraine, irritable bowel and ulcerative colitis where good studies in these areas have demonstrated effectiveness. While Ernst's information is comprehensive, as I have mentioned, his interpretation of that information is severely limited. He fails, as always in these simplistic texts, to address the issue of CAM as a whole system and in particular herbs used in combination. In pragmatic clinical practice, going to see a herbalist does not simply involve that trained individual in prescribing one particular herb. It almost always results in a mixture of herbs being prescribed provided in individualised consultation and frequently with some traditional Chinese basis to that prescription in the case of Eastern herbal practice. Lifestyle advice is often provided as part of that process. As a consequence, the conventional doctor reading the Oxford Handbook will be very mislead by the somewhat simplistic interpretation of both herbal research in this text and will find little guidance when confronted with a patient's mixed herbal prescription.

While Ernst has done an absolutely superb job in systematising a large amount of evidence, he fails to contextualise this by making it clear that there is an awful lot that we do not know. What he tends to do is simply interpret a lack of knowledge as negative evidence; this would place most primary care physicians in a quandary when faced with best practice guidelines which often represent the best we think we can do for the patient we are seeing with the limited evidence available. This theme is entirely in contradiction to the underlying principles of evidence based medicine suggested by Oxman and Sackett, but it has become a politically and culturally convenient 'peg to hang your hat on', particularly in CAM, and especially if you want to produce an over-simplistic solution to a complex problem. Unfortunately, the Oxford Handbook produces a lot of simple solutions to complex problems and runs the risk of being all the poorer for it.

Finally, we should address what is original about the Oxford Handbook of Complementary Medicine in comparison to the Desk Guide and the many other Ernst publications? Well frankly very little; salami comes to mind? The database is much the same as in other Ernst texts, so if you own one already, do not buy this one. If you do not own a similar Ernst text already, then buy this one. Ernst texts do have a lot to offer, but interpret them with caution; they come with a health warning!

George Lewith, Southampton

\begin{tabular}{ll}
\hline KARGER & $\odot$ 2008 S. Karger GmbH, Freiburg \\
Fax +49761 45207 14 & Accessible online at: \\
$\begin{array}{l}\text { E-mail Information@Karger.de } \\
\text { www.karger.com }\end{array}$ & www.karger.com/fok
\end{tabular}

